Reprinted from

Acute Diarrhoea in Childhood

Ciba Foundation Symposium 42 (new series)

published July 1976 by Elsevier/Excerpta Medica/North-Holland

ISBN 9021940477 and 0-444-15208-3

\title{
Breast-feeding, weaning and the diarrhoeal syndrome in a Guatemalan Indian village
}

\author{
LEONARDO J. MATA*, RICHARD A. KRONMAL+, BERTHA GARCiA \pm , WILLIAM \\ BUTLER+. JUAN J. URRUTIA \pm and SANDRA MURILLO* \\ *Instituto de Investigacion en , Salud, Universidad de Costa Rica, San Pedro, Costa Rica, \\ +School of Public Health and Community Medicine, University of Washington, Seattle, \\ Washington, and \pm Instituto de Nutrition de Centro America y Panama, Guatemala
}

Abstract Prospective studies in Mayan Indian children living in their natural setting were carried out from 1964 through 1974; observations began at birth and extended at least throughout the first three years of life. Adequate growth and survival were characteristic of exclusively breast-fed infants in the first months of life. Despite the high rate of infection, children exhibited a considerable resistance to intestinal protozoa, enterobacteriaceae and enteric viruses. Resistance against colonic invaders is attributed to the bifidus flora, and that against agents acting in the small bowel, to specific antibodies present in colostrum and milk. Diarrhoeal disease was least in this period and increased with weaning to reach maximum peaks at the time of weaning. The protracted weaning consisted of progressive administration of foods of low biological value given under deficient sanitary conditions.

The nutrient value of the diet as a function of the child's weight was adequate in protein but in most cases it was markedly deficient in calories. Infectious diseases, particulaily diarrhoea, were found associated with pronounced reductions in the already deficient calorie intake.

Infection and infectious disease were common particularly during the first 6 to 18 months of life. Weight loss was a frequent finding during and after episodes of disease. The consequence of the malnutrition-infection interaction is a marked stunting of growth, clearly evident from examination of the growth curves of village children.

Nutrient intake did not correlate with growth velocity. By contrast, the duration of breast-feeding was strongly associated with growth in the linear segment of the curve, while in the period of faster growth the correlation was inverse. On the other hand, morbidity was inversely correlated with calorie and protein intake and this was more obvious in the second than in the first year of life.

The data indicate that infection is one of the leading factors associated with reduced calorie (and protein) intakes during the critical period of onset of malnutrition and mortality in childhood. By preventing infection, particularly diarrhoea, the food intake, nutrition and growth of children could be significantly improved. 
Diarrhoeal diseases still rank among the leading reported causes of childhood morbidity and mortality in nations where malnutrition and deficient hygiene prevail. The inter-American investigation of childhood mortality by the Pan American Health Organization revealed that malnutrition frequently underlies deaths due to diarrhoea and other communicable diseases (Puffer \& Serrano 1973). This interrelation was recognized as a syndrome, 'weanling diarrhoea', many years ago in infants and small children (Gordon et a/. 1963).

The interdependence of weanling diarrhoea with the particular pattern of weaning is evident from the varying age of occurrence of the peak of diarrhoea in various geographical regions. Weanling diarrhoea appears early with early weaning and late when breast-feeding is prolonged. In early diarrhoea the probability of severe malnutrition and premature death and other sequelae is greater than when weaning is late. Prolonged weaning, nevertheless, is associated with malnutrition and mortality.

Numerous investigations have failed to show conclusively a satisfactory aetiological explanation for the endemic diarrhoeas, although epidemiological

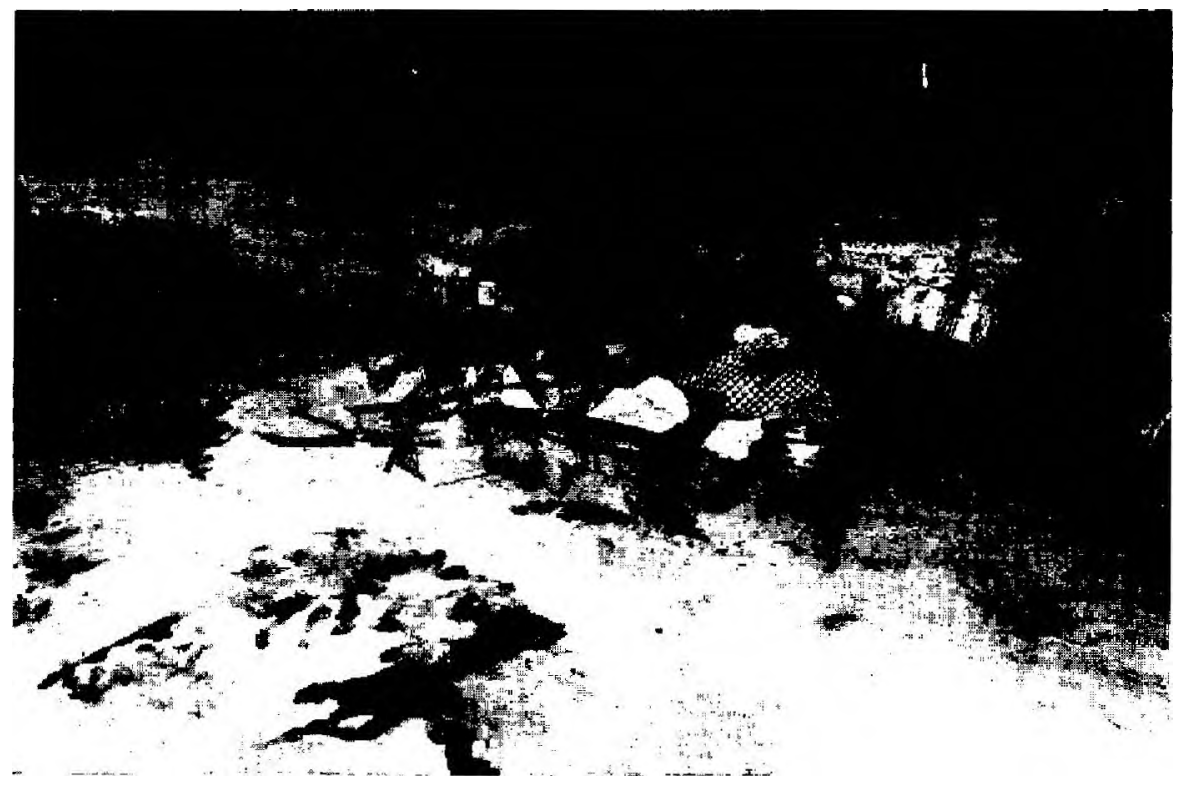

FIG. 1. A common scene in a village home in Santa Maria Cauque illustrates conditions surrounding the mother and child. The mother prepares the maize dough in a stone metate. In the background left is a tapesco or rustic bed used by all members of the family. At the background right is a large earthen jar, a $\operatorname{tin}^{*}$, to store the household water. The house has adobe walls and earthen soil. 
evidence indicates an infectious origin. The present paper does not deal with the complex question of aetiology but with the relationship of the diarrhoeal diseases with nutrition and health. Observations pertain to a long-term prospective study in a highland Guatemalan Indian village, Santa Maria Cauque, where children were observed from birth to preschool age in their natural setting (Fig. 1). Observations refer to the relationship between child feeding and diarrhoea, weight loss, reduced intake and impaired physical growth.

\section{FIELD PROCEDURE}

Beginning in 1964 and for two years, all infants born in the village were recruited at birth and studied according to a programme of periodic measurements of their physical growth, food intake, intestinal infection and general health condition. Details of the nature of the study and methodologies employed are given elsewhere (Mata et al. 1967; Mata \& Urrutia 1971; Mata et al. 1971, 1972a, $b$ ).

One feature of the study was the frequency with which observations were made ( Table I). The study placed an emphasis on home visits to minimize gatherings at the clinic which could favour iatrogenic contamination and dissemination of community infections. Weekly visits to the homes were made to record food intake. Infants were surveyed every week to determine the health condition, a practice permitting an early detection of morbidity and prompt diagnosis and treatment. The visits provided many opportunities for the collection of anthropometric observations.

The data collected were recorded in forms suitable for transfer to cards and

TABLE 1

Programme of examinations ${ }^{a}$ of 45 cohort children in Santa Maria Cauqué, 1964-1972

\begin{tabular}{|c|c|}
\hline Variable & Frequency of examinations \\
\hline Weight & $\begin{array}{l}\text { At birth } \\
\text { Daily, one week } \\
\text { Weekly, neonatal period } \\
\text { Fortnightly, 1st-12th month } \\
\text { Every } 4 \text { weeks, 2nd and } 3 \text { rd years }\end{array}$ \\
\hline $\begin{array}{l}\text { Breast-feeding \& } \\
\text { nutrient intake }\end{array}$ & $\begin{array}{l}\text { Weekly, from birth to } \\
3 \text { months after complete weaning }\end{array}$ \\
\hline Morbidity & Weekly, from birth to 3 years \\
\hline
\end{tabular}

- Only variables used in the analysis are listed in the table. 
further handling by digital computers. Standardization of techniques, periodic evaluation of methods, and systematic edition of forms were inherent features of this investigation.

\section{RESULTS}

Descriptions of this population and of findings relating to maternal and newborn characteristics, the diet and growth of children and the interaction of malnutrition and infection have appeared elsewhere (Mata et al. 1971, I 975a, 6; Urrutia et al. 1975). Only certain characteristics relevant to the subject of this paper will be summarized here.

\section{Breast-feeding}

About $10 \%$ of lactating women became pregnant and continued breastfeeding their infants through pregnancy and delivery. A third of those not lactating gave colostrum to their infants. In the remaining two-thirds a foster mother was available immediately after delivery. The mother offered the breast as soon as milk was secreted. Breast-feeding was always successful among infants surviving the first 48 hours.

The protection against infection and the good nutrition conferred by colostrum and maternal milk were factors contributing to the adequate growth rate in the first weeks of life. During the period of exclusive breast-feeding (two to four months in the village) infants were quite resistant to intestinal infection by enteric bacteria and protozoa. Early infection with shigellae and protozoa disappeared after one week (Mata \& Urrutia 1971; Mata et al. 1972a); the child's intestine was quite free of these agents for weeks or months, providing that maternal milk was the sole or main food received.

Soon after initiation of supplemental feeding, marked changes in the indigenous flora were detected. The child then becomes more susceptible to intestinal bacterial infection because foods are often contaminated and invasion is more feasible. The protective effect of maternal milk seems to be mediated by a variety of factors of which the indigenous bifidus flora and the specific secretory IgA appear most relevant.

High levels of secretory $\operatorname{IgA}$ were detected in colostrum and mature milk from Guatemalan Indian women (Fig. 2). Antibody levels in milk were high at all times and persisted throughout the entire length of lactation (Wyatt et al. 1972). A good correlation between antibody levels in milk and the antibody content of the child's faeces has been demonstrated (Gindrat et al. 1972).

Escherichia call gains access and implants in the child's intestinal tract 


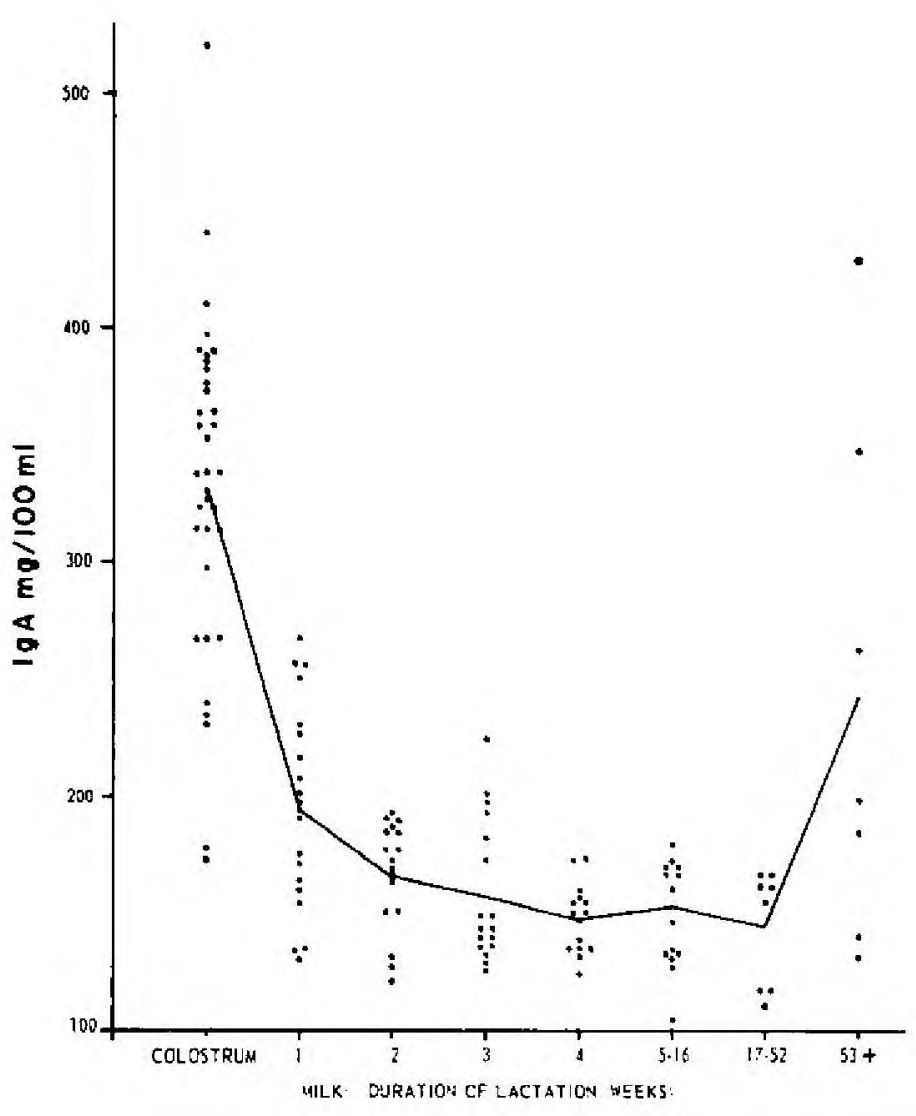

Fig, 2. Concentrations of secretory IgA in colostrum and milk of women from Santa Maria Cauque, 1968. The presence of significant concentrations of secretory $\operatorname{lgA}$ several months after the onset of lactation should be stressed. Women lactating for more than one year had values as high as those found in colostrum (Wyatt et al. 1972).

shortly after birth (Mata \& Urrutia 1971); it becomes partially suppressed later on and persists in low concentrations (Table 2). With the introduction of supplemental feeding, the coliform concentration rises to $10^{9}$ to $10^{\prime \prime}$ by midinfancy. There is no doubt that during breast-feeding the intestinal milieu is not optimal for coliform replication. With weaning, coliforms increase as well as the probability of replication of pathogenic E. coil and of bacterial invasion of the colonic mucosa. Breast-feeding protects against bacteria acting in the small and large intestine; the effect occurs during the period of exclusive breast-feeding. 
TABLE 2

Evolution of faecal flora in 12 breast-fed infants in Santa Maria Cauque, 1964-1969"

\begin{tabular}{lrccc}
\hline \multicolumn{5}{c}{ Age in weeks } \\
& $5-8$ & $13-16$ & $21-24$ & $95-48$ \\
\cline { 2 - 5 } & & & & \\
\hline Bifidobacteria & 11.1 & 11.4 & 11.6 & 11.0 \\
E. coil & 7.7 & 8.8 & 9.1 & 9.8 \\
Anaerobes & 11.5 & 11.6 & 11.6 & 11.2 \\
Aerobes & 8.0 & 8.8 & 9.2 & 9.8 \\
$\quad$ Anaerobes & 99.9 & 99.8 & 99.7 & 98.8 \\
\hline
\end{tabular}

From Mata \& Urrutia (1971).

Concentration of bacteria per gram of wet faeces $(\log 10)$.

In the Indian village, nursing continues for two years in most cases and occasionally for as long as three years or even longer. A slight trend toward an earlier weaning was demonstrated during ten years of prospective study.

\section{Supplemental feeding}

Infants were given broths and gruels not earlier than the fourth or fifth month of life. Solids were introduced at the end of the first year (Table 3). The amounts of foods consumed by the children are small as judged by the customary diet of weaned two-year-olds (Table 4).

Data of intake versus age displayed in scatter diagrams indicated considerable weekly variation but nevertheless were quite consistent. Correlation coefficients for individual children were relatively high with $R^{2}$ values greater than 0.6 for protein, calories and carbohydrates, as shown in Fig. 3.

An estimate of the weekly calorie and protein intake was made for every weaned cohort child, a total of 30 children. Observations were obtained for varying lengths and included all data collected. The child with least data had seven weeks of observation; that with most information had 66 weeks.

Estimates of the adequacy of the diet for age showed that 8 of 14 weaned twoyear-old children did not reach $50 \%$ of the recommended calorie intake; the rest were consuming intakes between 50 and $99 \%$ of the recommendation (Table 5). At three years of age the situation had improved but several children were still consuming very low calorie intakes. It is worth noting that protein deficiency was comparatively less than calorie deficiency.

The expression of recommendations by age is very stringent; it does not seem totally justified for populations like Santa Maria Cauque, because many 
TABLE 3

Number of infants consuming foods (measurable amounts) among 45 cohort children in Santa Maria Cauque, 1964-1967

\begin{tabular}{|c|c|c|c|c|c|c|}
\hline & \multicolumn{2}{|c|}{ Month of life } & \multirow[b]{2}{*}{10} & \multirow[b]{2}{*}{11} & \multirow[b]{2}{*}{24} & \multirow[b]{2}{*}{$36 b$} \\
\hline & 6 & 8 & & & & \\
\hline Dairy products & 2 & 2 & 1 & 2 & 8 & 33 \\
\hline Eggs & & $2^{\prime}$ & 14 & 15 & 29 & 16 \\
\hline Meats & & & $1 \mathrm{I}^{\circ}$ & 29 & 45 & 42 \\
\hline Beans & & & & 7 & 37 & 42 \\
\hline Vegetables & & 11 & 25 & 40 & 45 & 42 \\
\hline Fruits & 1 & 10 & 18 & 25 & 26 & 41 \\
\hline Bananas, plantain & & 17 & 36 & 39 & 43 & 41 \\
\hline Tubers, roots & & 5 & 10 & 11 & 22 & 25 \\
\hline Tortilla (maize) & 4 & 35 & 41 & 45 & 45 & 42 \\
\hline Bread & 10 & 37 & 44 & 45 & 44 & 42 \\
\hline Rice \& noodles & & 15 & 29 & 37 & 42 & 42 \\
\hline Sugar & 21 & 45 & 45 & 45 & 45 & 42 \\
\hline Broths, gruels & 1 & 27 & 45 & 45 & 45 & 42 \\
\hline Coffee & $\mathrm{II}^{\circ}$ & 36 & 43 & 44 & 45 & 42 \\
\hline
\end{tabular}

- Negligible amounts.

b 42 children alive at age 36 months.

TABLE 4

Customary diet of weaned two-year-old children in Santa Maria Cauqué, 1971

\begin{tabular}{lrr}
\hline Food & Mean grams per day & Percentage of diet \\
\hline Tortillas (maize) & 104 & 32.1 \\
Bread (wheat) & 20 & 6.2 \\
Rice, noodles & 16 & 4.9 \\
Potatoes & 4 & 1.2 \\
Sugar & 29 & 9.0 \\
Black beans & 48 & 14.8 \\
Beef & 5 & 1.6 \\
Egg & 8 & 2.5 \\
Vegetables & 21 & 6.5 \\
Banana, plantain & 16 & 4.9 \\
Fruits & 13 & 4.0 \\
Beef broth & 26 & 8.0 \\
Bean broth & 12 & 3.7 \\
Coffee & 2 & 0.6 \\
\hline
\end{tabular}




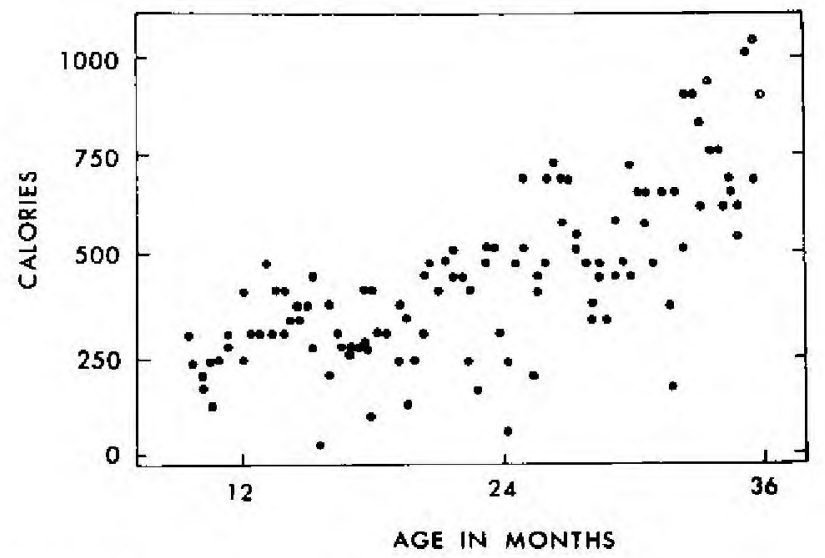

Fig. 3. Scatter diagram of intake of calories versus age, child No. 3 from Santa María Cauqué. The correlation coefficient $(r)$ was 0.7 . Calories are highly correlated with protein. About one half of the total intake is derived from maize prepared as tortillos, flat cooked pancakes of lime-treated corn.

children are already small at birth ana are definitely underweignt (luring infancy and the preschool period, relative to the children on whom the standards are based. The standard in question is the Iowa (Jackson \& Kelly 1945), adopted by INCAP (1956).

The adequacy of the diet, therefore, was calculated as a function of body weight using Sukhatrne's approach (1974). A fixed value of $100 \mathrm{kcal}$ and $1.25 \mathrm{~g}$

TABLE 5

Adequacy of the diet of children weaned at two and three years of age, as a percentage of recommendation, in Santa Maria Cauque, 1964-1970

\begin{tabular}{|c|c|c|c|c|}
\hline \multirow{2}{*}{$\begin{array}{l}\text { Percentage of } \\
\text { recommendation }\end{array}$} & \multicolumn{3}{|c|}{ Recommendation for age } & \multirow[b]{2}{*}{ Protein } \\
\hline & & & Calories & \\
\hline \multicolumn{5}{|l|}{14 two-year-olds } \\
\hline$<50$ & $8 \mathrm{a}$ & 2 & & \\
\hline $50-99$ & 6 & $\mathrm{I} 2$ & & \\
\hline $100<$ & 0 & 0 & & \\
\hline \multicolumn{5}{|l|}{28 three-year-olds } \\
\hline$-c 50$ & 2 & 2 & & \\
\hline $50-99$ & 18 & 18 & & \\
\hline $100-$ & 8 & 8 & & \\
\hline
\end{tabular}

Number of children. 
of protein per kilogram of body weight was assumed to be the recommendation (FAO/WHO 1973).

Since dietary intakes were obtained on a weekly basis, 'recommended calorie (or protein) intakes' were calculated per week using the closest weight measurement at each week for which dietary data were available. The percentage of recommended calories (or of protein) of a particular child in a particular week became:

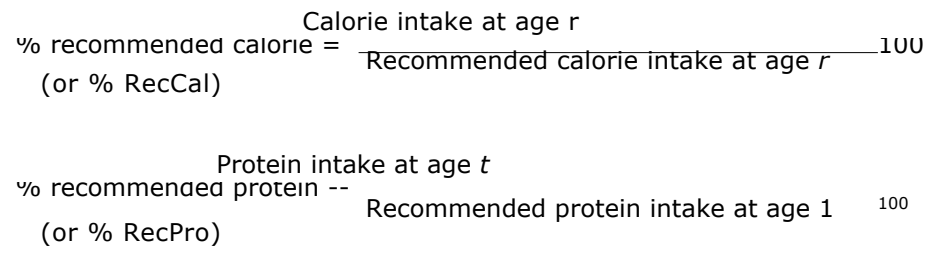

As indicated before, computations were only for children reported totally weaned. The \%RecCal for five consecutive weeks of a child, were, for instance, 94, 62, 65, 69 and 50. The pattern of distribution of the \%RecCal estimates of one of the children with the highest intakes is shown in Fig. 4; it shows marked deficits in the six-month period following weaning. Thereafter, levels were about or above 100\%, except in occasional weeks where intakes were reduced. One of those, at about 33 months of age, was very drastic and coincided with an infectious disease episode.

Among 30 weaned children, 24 had values of \%RecCal above 99 in at least one week but six had all their values below $100 \%$.

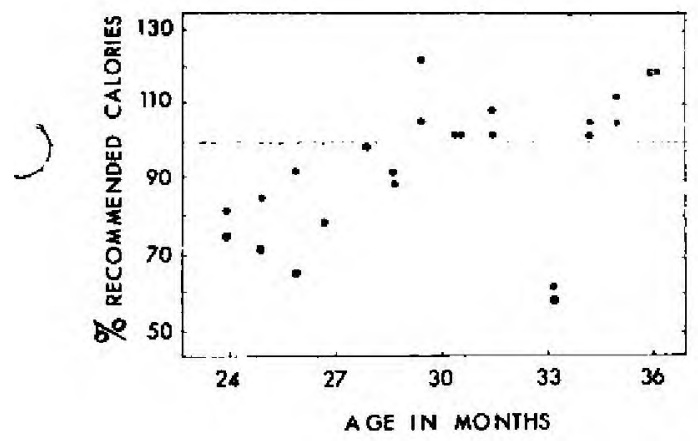

FIG. 4. Estimates of \% recommended calories ( $\%$ RecCal) consumed by child No. 37 from Santa Maria Cauque. Each dot is a weekly estimate. This child, among those with the highest intake, had low \%RecCal values in the six-month period after complete weaning. Intake improved thereafter, but at 33 months of age a significant reduction in caloric intake was noted in conjunction with an infectious disease. 
This manner of estimating the value of the diet appears more realistic under field conditions; it is less affected by such characteristics as birth weight, gestational age, growth and individual variability and background experience affecting body size than the estimates based on age.

In order to summarize all the weekly data of individual children, the 'mean percentage recommended calorie (or protein)', abbreviated M\%RecCal (or M $\%$ RecPro), was calculated. This variable represents the child's level of recommended calorie (or protein) intake, and consists of the sum of all \% Rec Cal ( or \%RecPro) data points for a given child, divided by the number of points:

$$
\mathrm{M} \% \mathrm{RecCal} \quad \% \mathrm{ReeCal}_{1} \% \operatorname{RecCal}_{\mathrm{i} \ldots \ldots \ldots \ldots \ldots \ldots \ldots \ldots \ldots \ldots \ldots} \% \operatorname{RecCal},
$$

Among 30 wholly weaned children, none had a mean percentage recommended protein (M\%RecPro) under 100. All but one had M\%RecCal of less than 100; many had very low M\%RecCal figures. This implies that children's diets, on the whole, were not deficient in protein, but instead calorie deficient, as Sukhatme ( 1974) had shown to be the case for certain Indian populations. It is clearly evident that the apparently small amounts of protein in the village diet are an adequate complement to the diet. In fact, the percentage of calories from net dietary protein (NDpcal \%) is of the order of 6.

The summary of the analysis for all children is shown in Table 6. There were only two diets available for fully weaned 18-month-old children. The results indicate that there is practically no protein deficiency. A marked calorie deficiency was observed at age two years, with three-quarters of the children

TABLE 6

Adequacy of the diet of weaned children, by weight, in Santa Maria Cauque, 1964-1970

\begin{tabular}{llll}
\hline \multirow{2}{*}{ Age in months } & Protein & Calories & \\
\cline { 3 - 4 } & & Adequate & Inadequate \\
\hline \multirow{2}{*}{18} & Adequate & 0 & 0 \\
& Inadequate & 0 & $2^{\prime}$ \\
24 & Adequate & 3 & 9 \\
\multirow{2}{*}{36} & Inadequate & 0 & 2 \\
& Adequate & 15 & 15 \\
& Inadequate & 0 & 0 \\
\hline
\end{tabular}

The diets of only two weaned children were available at 18 months; they were calorie and protein inadequate. 
having deficits. There was some improvement at age three years but still one half of the children had calorie-deficient diets. Nevertheless, such an improvement is indicative of the trend in populations to improve the nutrient intake as a function of age.

\section{Morbidity}

The systematic and consistent supervision of each cohort child yielded a rather complete morbidity record which revealed frequent disease episodes often associated with each other, as shown in Fig. 5. By definition, the absence of symptoms or signs for more than one day arbitrarily differentiates between two

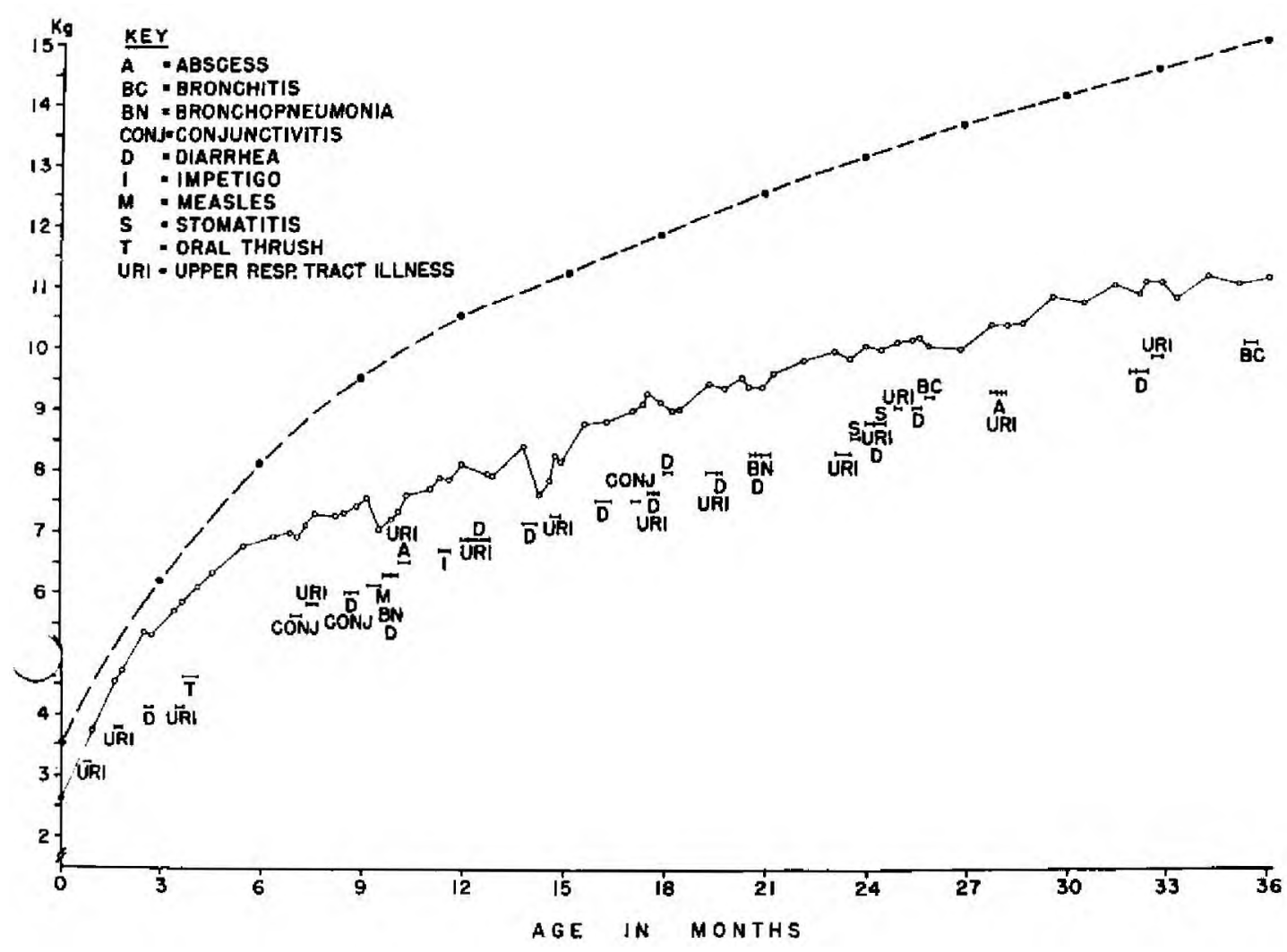

FIG. 5. Life chart of one child from Santa Maria Cauque, from birth to three years of life, showing the weight curve in comparison with the median of the Iowa standard (Jackson \& Kelly 1945). Illnesses are shown under the curve; duration of illness is represented by the length of the horizontal lines. 
illnesses. Morbidity in the first three years of life was mainly gastrointestinal and respiratory (Table 7). Illnesses of the upper respiratory tract, mainly colds, accounted for $20 \%$ of all events. More serious respiratory illnesses occupied a less, but not least, important role. Bronchitis and bronchopneumonia, for instance, accounted for $13 \%$ of all episodes. Gastrointestinal disorders were more frequent and of an apparently greater importance. They represented $43 \%$ of all illnesses, of which the dysenteric varieties were a third.

Although in many instances it was impossible to determine associations between disease and weight loss because morbidity appeared in a continuum, well-marked indentations were appreciable in the weight curves of some children in connection with the establishment of diarrhoea! disease (as for example in

TABLE 7

Cases and relative frequency ( $\%$ ) of infectious illnesses among 45 cohort children observed from birth to age three years in Santa Maria Cauque, 1964-1969

\begin{tabular}{|c|c|c|c|}
\hline Class & Illness & Cases & Percentage \\
\hline \multirow[t]{6}{*}{ Respiratory } & Upper respiratory tract & 493 & 20.14 \\
\hline & Tonsillo-pharyngitis & 10 & 0.41 \\
\hline & Bronchitis & 256 & 10.46 \\
\hline & Bronchopneumonia & 70 & 2.86 \\
\hline & Other & 18 & 0.74 \\
\hline & & & 34.60 \\
\hline \multirow{4}{*}{ Gastrointestinal } & Diarrhoea & 640 & 26.14 \\
\hline & Diarrhoea with mucus & 313 & 12.79 \\
\hline & Dysentery & 97 & 3.96 \\
\hline & & & 42.89 \\
\hline Eye, Ear, Mouth, Throat & & 337 & 13.77 \\
\hline \multirow[t]{7}{*}{ Common communicable diseases } & Measles & 32 & 1.31 \\
\hline & Rubella & 15 & 0.61 \\
\hline & Varicella & 26 & 1.06 \\
\hline & Whooping cough & 10 & 0.41 \\
\hline & Exantherns & 29 & 1.18 \\
\hline & Other & 7 & 0.29 \\
\hline & & & 4.86 \\
\hline Other & & 89 & 3.64 \\
\hline
\end{tabular}


Fig. 5). The interaction between infection and malnutrition has been discussed elsewhere (Mata et al. 1971, 1972b).

The morbidity data served to calculate indices that were used in analysis with growth and diet variables. Rates of infectious disease (ILL, Table 8) were computed for every child, and for each of the first three years as well as for the total three-year period, by adding days of illness and dividing by the number of days of observation. Figures were for respiratory (RESP) and diarrhoeal ( DIAR) illnesses and for illnesses combined (ILL). For instance, the diarrhoeal rate of a particular child in the second year of life (DIAR 2) was 0.2 (see Tables 8 and 10).

TABLE 8

Variables used in regressions ${ }^{\circ}$

\begin{tabular}{ll}
\hline \multicolumn{1}{c}{ Growth } & $a$ - estimate at age zero \\
Intake & $\mathrm{b}$ - 'linear' parameter \\
& $\mathrm{e}=$ growth deceleration \\
Diseases & $\mathrm{M} \%$ RecCal \\
& M YoRecPro \\
& Respiratory - RESPI, RESP2, RESP3, RESPT \\
& Diarrhoea] = MARI, DIAR2, D1AR3, DIART \\
& All infections - ILLI, ILL2, IIL3, ILLT \\
\hline
\end{tabular}

${ }^{\circ}$ See text.

\section{Growth}

Infants grew adequately in the first weeks of life even if they had been small at birth. At two to four months, growth curves began to depart from the standard; virtually all children were markedly retarded by two years of age ( Mata et al. 1971, 1975a). The correlation between newborn variables and weight and height obtained at school age, as well as the parallellism of the mean growth curves of children defined by fetal maturity, are evidence that children tended to grow within their tracts defined by antenatal events (Mata et al. 1975b).

The frequent anthropometric measurements collected for the first three years of life permitted fitting the data by a mathematical formula $(y=a \pm b x$ $c \log \mathrm{x})$ according to Tanner (1962). Three parameters are identified for curves of individual children: $a$ is an estimate of the parameter at age zero (departing point); $b$, or 'linear' parameter, is a measure of the rate of growth reflecting 


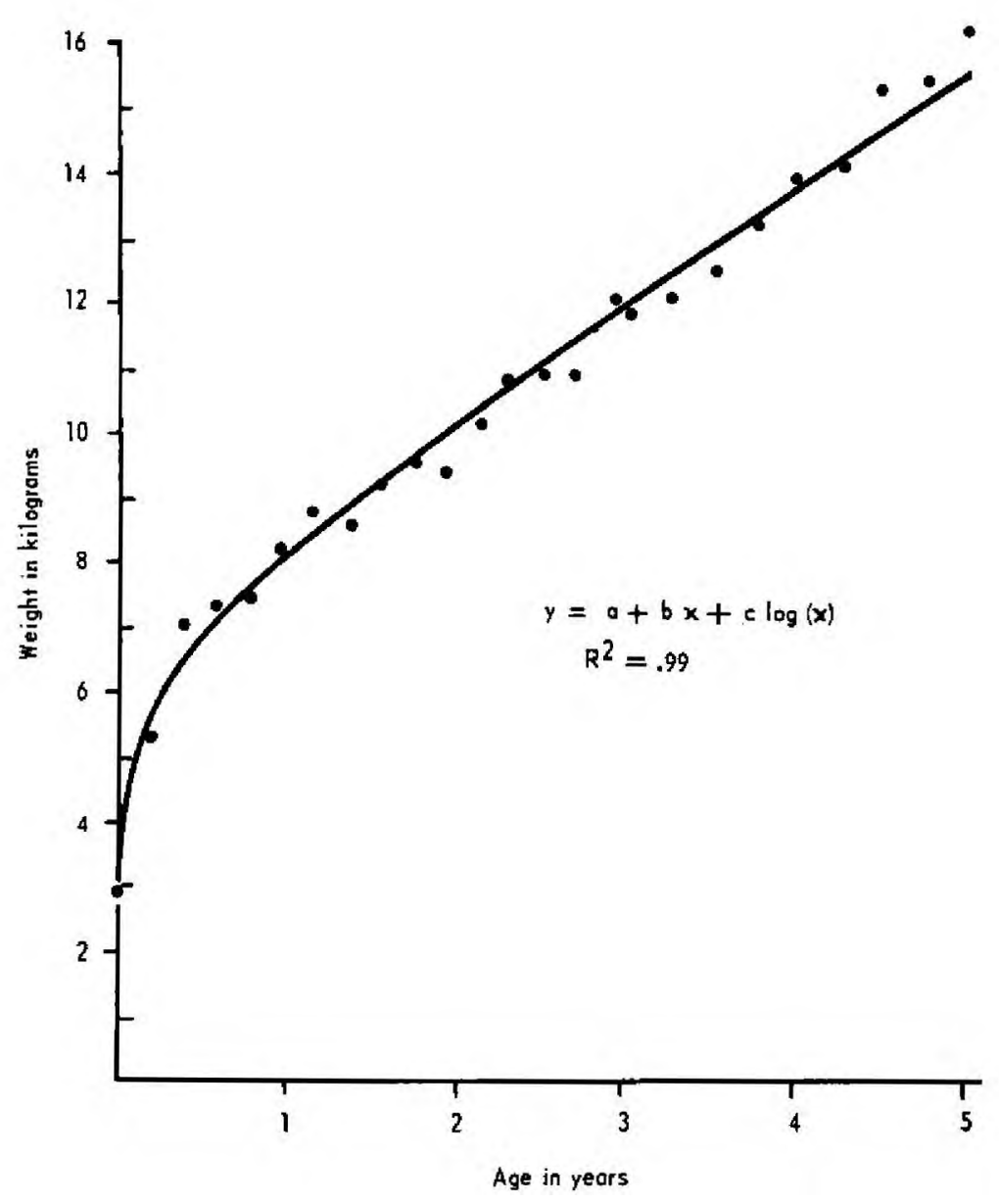

FiG. 6. Fitting of weight points of child No. 35 from Santa Maria Cauque, from birth to five years. The solid line was drawn from values of the estimated curve. The actual data are represented by dots. The high $\mathrm{R}^{2}$ value reveals an excellent fitting.

most of the growth trend after the period of fast growth; and $c$ the parameter of growth deceleration, reflecting growth in the first months of life. This treatment, used for growth data by Malcolm (1970), has given excellent fittings with long-term data from the Cauque study. For instance, Fig. 6 shows original data and their fitting for a particular child of the cohort (Mats et al. 1972a). Among growth curves of 208 children obtained by prospective observation, all but three gave $\mathrm{R}^{2}$ values in excess of 0.9 after fitting the data of the first three years of life. 
By a simple regression equation, weaning age (the age in months at which a child becomes fully weaned) correlated strongly with parameter $b$ (linear growth) of the weight and height curves. The correlation coefficients observed were of the order of 0.5 and 0.7 , significant at the $0.005 \%$ level. On the other hand, a negative correlation (-0.4) was noted with parameter $c$, significant at the $0.01 \%$ level. These associations imply that a prolonged weaning correlates with the largest portion of the growth curve $(b)$. Infants growing faster in the first year, are weaned earlier. The computed mean growth curves of all cohorts of the study, as defined by the age at which weaning was complete (weaning age), are shown in Fig. 7. It was revealed that indeed children weaned earlier were larger in the first year of life, while those weaned late had been smaller in the first year. Both groups were virtually identical in weight and height at 42

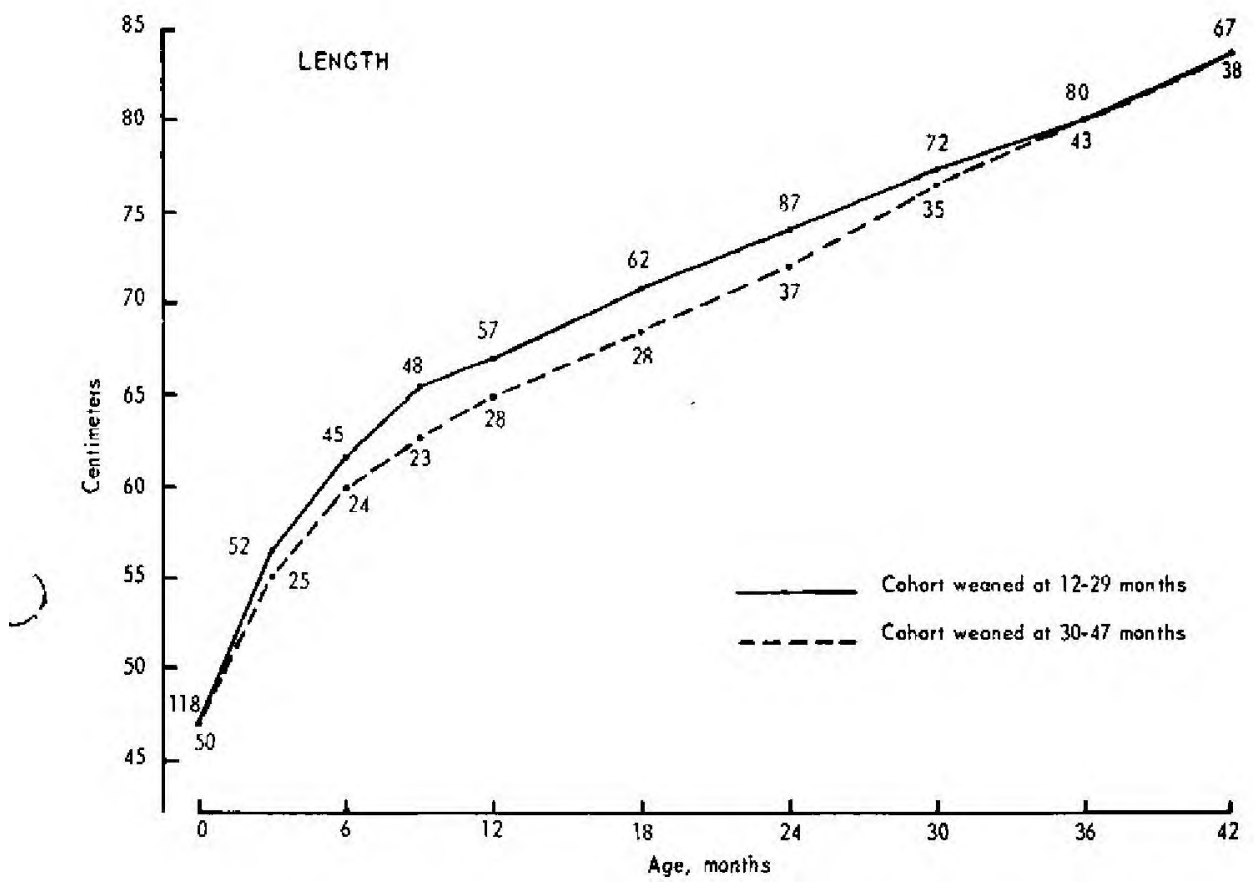

FIG. 7. Graphic representation of the means of body length, at fixed age intervals, of two cohorts of children from Santa Maria Cauque defined by the duration of breast-feeding. The cohort weaned 'early' (12 to 29 months) grew faster at the beginning. The other cohort, weaned late (30 to 47 months), grew more slowly earlier but faster at a later date than the 12 to 29 months cohort. The differences eventually disappeared. 
months of age. The correlation of the duration of breast-feeding with growth was the strongest of all those tested and in multiple regression analyses it explained the largest portion of the variance, about $16 \%$.

\section{Correlation between diet, growth and morbidity}

The variables used in the regression analysis are shown in Table 8. The growth parameters were correlated with the $M \%$ RecCal and M\%RecPro values. No significant correlations were found between nutrient intake and the parameters ( Table 9). Of interest is the finding that the slopes of the linear regression of nutrients in the diet do not correlate well with physical growth (Mata 1976). No explanation for this lack of correlation is available, particularly as food intake and age are so well correlated. The considerable variability of intake of individual children could have minimized the opportunities for correlation.

\section{TABLE 9}

Correlations between calorie and protein intake and growth (weight) for 30 weaned children in Santa Maria Cauque, 1964-1970

\begin{tabular}{llc}
\hline $\begin{array}{lll}\text { Parameter of } \\
\text { fitted growth curve }\end{array}$ & M\%RecCal & M\%RecPro \\
\cline { 2 - 2 }$a$ & & \\
\cline { 2 - 2 } & $-0.068 \mathrm{I}^{\circ}$ & -0.2686 \\
& $0.363^{\mathrm{h}}$ & 0.079 \\
$b$ & & \\
& -0.1582 & -0.2472 \\
& 0.206 & 0.098 \\
$c$ & -0.0039 & -0.0827 \\
& 0.492 & 0.335
\end{tabular}

- Correlation coefficient ( $r$ ).

${ }^{\text {"}} P$ value.

With regard to morbidity, several significant correlations were observed (Table 10). All the correlation coefficients with $M \%$ RecCal were of negative sign; $P$ values for rates of respiratory, diarrhoea' and total illnesses in the second year of life (RESP2, DIA R2 and ILL2) were significant. Likewise, all coefficients with $M \%$ RecPro except one were of negative sign and had significant $P$ values for the three groups of illness in the second year of life, excepting the rate of respiratory illness (RESP2), which had a borderline $P$ value of 0.059 .

No significant correlation was observed between intake and morbidity in the 
TABLE 10

Correlations between calorie and protein intake and morbidity of 30 weaned children in Santa Maria Cauque, 1964-1970

\begin{tabular}{lcc}
\hline Morbidity rate & M\%ReeCal & M\%ReePro \\
ILL i & -0.1124 & $0.0860^{\prime}$ \\
& 0.281 & $0.329^{\prime}$ \\
I L L2 & -0.4041 & -0.3446 \\
& 0.015 & 0.034 \\
I LL3 & -0.1368 & -0.0617 \\
& 0.240 & 0.375 \\
I L LT & -0.2230 & -0.2963 \\
& 0.123 & 0.059 \\
RESP I & -0.0190 & -0.0777 \\
& 0.461 & 0.344 \\
R ES P2 & -0.4226 & -0.2961 \\
& 0.011 & 0,059 \\
RESP3 & -0.0296 & -0.0084 \\
& 0.439 & 0.483 \\
RES PT & -0.3840 & -0.3246 \\
DIAR1 & 0.020 & 0.043 \\
DI A R2 & -0.2480 & -0.2262 \\
DIAR3 & 0.097 & 0.119 \\
DIA RT & -0.3758 & -0.3247 \\
& 0.022 & 0.043 \\
\hline
\end{tabular}

Correlation coefficient $(r)$.

- $P$ value.

first or the third years of life. Morbidity in the first year should not be strongly related to food intake because the food intake variables correspond to the second and third years of life, when weaning was effected. The lack of significant correlation for the third year could be explained by the fact that children are more adapted to the adverse environment in that period and therefore can cope with morbidity more successfully, as a result of both acquired resistance and better nutritional state. The strongest correlations corresponded to the second 
year of life, in this culture the time of highest incidence of weanling diarrhoea and of other infectious diseases as well. This is an important finding in that the food intake variables are a very imprecise measure of the second year intake since they include more third year data than second year, due to the late weaning of many children.

\section{DISCUSSION}

The importance of breast-feeding for the nutrition and health of young infants has been emphasized in recent times. The benefit of several months of breastfeeding stems from its nutritional value and the capacity of maternal milk to protect against infectious agents of the diarrhoeal syndrome. This property is of greater relevance for developing countries where the diarrhoeas are among the most important health problems.

The role of the diarrhoeal syndrome in the aetiology and outcome of malnutrition was recognized long ago. Children living in insanitary environments are susceptible to infection with a variety of agents that may lead to disease and death. After the period of exclusive breast-feeding, resistance decreases and the child experiences frequent infections and bouts of diarrhoea which are often accompanied by weight loss, growth faltering and sequelae of various sorts.

Concomitantly, deficient weaning by mothers lacking the knowledge and resources to do otherwise, leads to a state of chronic caloric deprivation and progressive deterioration of the nutritional state. The apparent deficit of proteins resulted from comparison with requirements set for normal children of the same age but of larger size. When reference to weight is made, the diets appear adequate for proteins. A deficit of calories, however, is observed and it is the most, and probably the sole, important nutrient deficiency in the region. The aetiology of the low calorie intake is not well understood in every case. The nature of the available foods in the area could determine a low acceptability by the child during the critical ablactation period. Maize and beans have a high content of fibre and starches and digestibility is not optimal. Maternal education is also an important factor because it determines the nature and techniques of weaning. Village mothers generally do not prepare adequate mixes and purées; they have inadequate composition and poor consistency and hygiene. The economic capacity of the family, particularly the resources available to the mother, are of considerable importance because they determine food availability and the conditions under which foods are prepared.

Infection plays a leading role in the process of ablactation. The living conditions in village homes favour the transmission of gastrointestinal and 
respiratory infectious agents. Eventually, all infants become infected with a wide variety of aetiological agents and experience many episodes of infectious disease. -Morbidity is clearly associated with malnutrition and growth failure. The examination of individual growth charts indicates that bouts of diarrhoea result in weight loss and arrest of growth. Recuperation may last several weeks or months. The occurrence of diarrhoea and of other illnesses is a frequent phenomenon. Thus, their overall effect on growth is important.

Impaired food intake, particularly of calories, is highly correlated with the occurrence of illnesses in the second year. No correlation was demonstrated with morbidity rates in the third year. While it is not certain whether the correlations observed indicate a primary effect of the diet or of the disease, the particular living conditions and sanitary environment of this population suggest that infection, particularly gastrointestinal, is a primary factor in this interaction. Thus, the child becomes infected especially during weaning and often develops diarrhoea. Food intake is reduced. Thus, the effect on nutrition is due to alterations caused by the infectious process as well as to an impaired nourishment resulting from reduced intakes, malabsorption and increased nutrient losses.

It is then clear that improvement in environmental sanitation, personal hygiene and housing conditions would bring about a significant reduction in rates of infection which, by itself, would represent an important contribution to the nutritional state.

\section{References}

FAO/WHO (1973) Energy and protein requirements. WHO Tech. Rep. Ser. No. 522, 118 pp GINDRAT, J. J., GOTHEFORS, L., HANSON, L. A. \& WINBERG, J. (1972) Antibodies in human milk against $E$. col( of the serogroups most commonly found in neonatal infections. Acta Paediatr. Stand. 61, 587-590 GORDON, J. E., CHITKARA, I. D. \& WYON, J. B. (1963) Weanling diarrhoea. Am. J. Med. Sci. 245, 345-377

INCAP (1956) Evaluation del Estado Nutritional, Publ. No. 9, Series Ensenando Nutrition, INCAP, Guatemala

JACKSON, R. L \& KELLY, G. (1945) Growth charts for use in pediatric practice. J. Pediat. 27. 215-229

$q$ MALCOLM, L. A. (1970) Growth and Development in New Guinea-A Study of the Bundi People of the Madang District, Institute of Human Biology, Papua-New Guinea, Monograph Ser. No. I, Surrey Beatty \& Sons, New South Wales, 105 pp.

MATA, L. J. (1976) The Children of Santa Maria Calque. A Prospective Study of Health and Growth, The MIT-Cornell Press, Cambridge, Mass., in press

MATA, L. J. \& URRUTIA, J. J. (1971) Intestinal colonization of breast-fed children in a rural area of low socio-economic level. Ann. N.Y. Acad. Sci. 176, 93-109 
MATA, L. J., URRUTIA, J. J. \& GARCIA, B. (1967) Effect of infection and diet on child growth: experience in a Guatemalan village, in Nutrition and Infection (Ciba Found. Study Group 31), pp. 112-126, Little Brown, Boston and Churchill, Edinburgh

MATA, L. J., URRUTIA, J. J. \& LECHTIG, A. (1971) Infection and nutrition of children of a low socioeconomic rural community. Am. J. Clin. Nutr. 24, 249-259

MATA, L. J., URRUTIA, J. J., CACERES, A. \& GuzidArq, M. A. (1972a) The biological environment in a Guatemalan rural community. Proc. Western Hemisph, Nutr. Congress III, pp. 257-2M, Futura Publishing $\mathrm{Co}_{\text {, }}$ New York

MATA, L. J, URRUTIA, נ. J., ALBERTAZZI, C., PELLECER, O. \& ARELLANO, E. (1972b) Influence of recurrent infections on nutrition and growth of children in Guatemala. Am. $J$. abr. Nutr. 25, 1267-1275

MATA, L. J., URRUTIA, J. J., KRONMAL, R. A. \& Jopl1N, C. (1975a) Survival and physical growth in infancy and early childhood. Am. J. Dis. Child. 129, 561-566

MATA, L. J., KRONMAL, R. A., URRUTIA, J. J. \& GARCIA, B. (1975b) Antenatal events and postnatal growth and survival of children. Prospective observation in a rural Guatemalan village. Proc. Western Hemisph. Nutr. Congress IY (White, P. L. \& Selvey, N., eds.), pp. 107-116, Publ. Sciences Group, Mass.

PUFFER, R. R. \& SERRANO, C. V. (1973) Patterns of Mortality in Childhood, Pan American Health Organization Sci. Publ. No. 262

SUKHATME, P. V. (1974) The protein problem, its size and nature. J.R. Statist. Soc. 137, 166-199

TANNER, J. M. (1962) Growth at Adolescence, Blackwell Scientific Publications, Oxford URRUTIA, J. J., MATA, L. J., TRENT, F., CRUZ, J. R., VILLATORO, E. \& ALEXANDER, R. E. (1975)

Infection and low birth weight in a developing country. Am. J. Dis. Child. 129, 558-561 WYATT, R. G., GARCIA, B., CACERES, A. \& MATA, L. J. (1972) Immunoglobulins and antibodies in colostrum and milk of Guatemalan Mayan women. Arch. Latinoamer. Nutr. 22, 629-644

\section{Discussion}

Rohde: This paper opens up a real Pandora's box, Dr Mata, because what you are saying, and 1 am a complete convert to your concept, is that infection isn't necessarily mainly important for what it does catabolically to the body, as for example in the case of nitrogen losses with typhoid fever or of catastrophic measles, but that even more universally important is the fact that children who are not feeling well won't eat. One sees a picture of frequent minor illness, which those of us wrestling with the concepts of health care delivery are inclined to dismiss as minor illness that we won't pay attention to, because we want to cover the 'major' problems. We may be making a bad mistake here. It may be the frequent small colds, minor ear infections and so on which are accounting for the attendant decrease in calorie intake. This gives the problem of health care delivery a new dimension, for repeated minor illness may be a vital factor in significant malnutrition. We have to reassess our priorities, which have tended to focus on major illness and preventable diseases, and give more attention to the minor daily ailments of small children. 
Hamilton: Am 1 right that you suspect that diarrhoeal disease in particular and perhaps some of the other infections too are more prolonged, or are they more severe in the undernourished?

Mata: We are not sure if disease is always more severe; we have the impression that for certain exanthematic manifestations it may be the other way round-that is, less severe in the malnourished child. This may be related to the manifestation of cell-mediated immunity, which is better in well-fed children. Regarding diarrhoea, severity, measured clinically, is greater in malnourished children in terms of mortality. Virtually all infectious diseases behave similarly, according to data compiled from many societies all over the world.

Duration, a measure of severity, is longer in malnourished children. The carrier state in shigellosis is much prolonged, lasting for months. At least 20 of the children with primary Shigella infections shed the agent for nine weeks (Mats et al. 1969). Scheifele \& Forbes (1972) showed prolonged excretion of measles virus within giant cells in children with malnutrition. There is a failure not only of the intestinal mucosa but of the intracellular apparatus to eliminate the infectious agent rapidly.

Hamilton: One of the ideas we were cautiously exploring earlier in the symposium is the importance of the differentiation of the intestinal epithelial cell as it migrates along the villus. This is one phenomenon that is likely to be sensitive to undernutrition, and perhaps provides a lead into one aspect of this relationship.

Hendrickse: Dr Mata and I both took part in an earlier meeting here on the interaction of nutrition and infection (Ciba Foundation 1967). This is a huge subject. I think Platt (1954) was the first to suggest that the quickest way to alleviate protein calorie malnutrition was to direct attention at the infections, and arising from this there have been many misdirections of effort. People have tried to take short-cuts to relieve the twin problems of malnutrition and infection of children in the Third World by specific immunization programmes, notwithstanding the fact that available vaccines protect from only a small fraction of the infections that are prevalent. Not surprisingly, these short-cuts have failed. There are no short-cuts. Dr Mata would be the first to agree that while his data show the importance of infections in relation to children's growth, nutritional state and so forth, the two things, nutrition and infection, are interwoven, and an approach to this kind of problem must surely be a double one. The malnourished child, subjected to, say, measles, does have a more severe illness. He not only goes on excreting virus but has been shown to have a protein-losing enteropathy (Dossetor \& Whittle 1975). This, of course, aggravates the nutritional condition. It is a complex situation in which one can become involved in circular arguments. A further danger is that 
statements from meetings like this one have sometimes been taken out of context to initiate lines of action which have sometimes wasted millions of pounds, and years of effort, by focusing on one facet of a complex situation and attempting short-cuts to alleviate the problems of the Third World. We should guard against this.

Maw: There is one aspect needing more consideration. If data show that protein deficiency is the most important deficiency in a community, you provide protein; when you realize that the limitation is of calories and that this is due in part to repeated infections, other alternatives for public health action are in view. We have recent examples of how much can be accomplished by simple educational measures, like teaching the boiling of water, or mixing foods in various ways, without necessarily going into supplemental feeding programmes. One study in Colombia showed that with education, immunizations and an improved water supply, a definite improvement in nutritional status was achieved without changing dietary practices or the food intake ( Aguirre \& Pradilla i973).

Hendrickse 1 agree with what you say about the wrong emphasis on protein. It infuriated me in West Africa that an available source of carbohydrate was spurned because it was said that cassava was a bad food because of its low protein content, and as a result children were denied carbohydrate. In a situation where calories were needed, people were being prejudiced against one of the few available sources of calories. Your studies are elegant; they refer to a particular population. I am certain that people in other areas can pinpoint other factors, and while what you say is perfectly valid for the population you studied, it does not necessarily apply elsewhere in its entirety, though there are lessons that should be applied in other areas. I am pleading that we accept this as a complex problem with many facets and shades worldwide. There may be situations where nutrition education alone could produce meaningful changes; but I am reminded of the words of Gandhi, who said that if God doesn't take the shape of food in parts of India, he had better stay away. With all the nutrition education in the world you can't provide calories if they are not available. We must not try to make the equation too simple.

Tarres-Pinedo: Dr Mata, you say that the protein intake is adequate for the weight of the children although not adequate for their age, according to the usual parameters, but that the caloric intake is low for their weight. That means that their weight will be progressively retarded in relation to age; then they will keep their protein intake proportional to their increasingly deficient weight, which means that the children have increasingly deficient protein nutrition.

Maw: I think that is true; one should calculate how much extra protein 
and calories are needed to correct for the retardation of weight for age. Torres-Pinedo: We know that the protein intake does not all go to body protein; some is broken down through other pathways. If the children are having a low caloric intake, I presume it is mostly due to a low carbohydrate intake. It means that they must use more protein for gluconeogenesis, and that protein will thus not be used to build body mass.

Mara: It depends on where you put your priorities in correcting the problem. If you increase protein intake significantly, you prevent deficiencies in calories, because protein is broken down, but at a high cost, to meet energetic demands. From the practical point of view you cannot do that; protein is expensive everywhere. One finds protein deficiency in children, because part of the dietary and body proteins are diverted to gluconeogenesis, as you say. If you calculate the percentage of calories derived from net dietary protein you find that it is adequate, about $6 \%$. You can increase the protein, but it is more logical to increase the calories, and it will cost less.

Torres-Pinedo: But if you increased the caloric intake without increasing the protein intake, you would produce kwashiorkor.

Mata: Yes. However, it is in fact very difficult to increase calories at the village level without increasing protein: you usually do it with bread, noodles or potatoes, and these foods contain protein.

Edsall: To return to Professor Hendrickse's comments, although admittedly I have usually looked at such problems in terms of their solution through immunization, I agree that that is not the answer in the situation you are talking about, Dr Mata. But there is a great deal of evidence that simply to improve the water supply has caused changes in the extent of diarrhoea and in the extent of clinical infection in some communities. Can you expand on that or verify that, or tell me if in one of your three model villages just one variable was altered, or did they receive education and sanitation and improved water?

Mata: The three-village study may not be a good example with which to answer you. Much money has been invested in water supplies and latrines, but the impact of these measures on community health has not been quantified, although they show their importance. For example, when measles is prevented, one is also preventing bronchitis, pneumonia, diarrhoea, blindness and other complications of measles. So the impact of the measures is much greater.

The information on water supply comes from studies in Fresno County in the USA (Hollister et al. 1955) and studies in Egyptian villages which show how important it is to have the water supply close to the home, and to increase the volume rather than the quality. Rates of Shigella and diarrhoeal disease are drastically reduced just by introducing a water supply (Floyd et al. 1956). 
I don't know of studies that have estimated the economic advantages of these measures or the implications in terms of expected mortality and morbidity, but it would not be difficult to calculate this. 1 tend to believe that there has been a nutritional craze spreading into the Third World nations, when peoples in the western nations have learnt to eat well most of the time. These nations reached that stage after they had a sufficient control of the environment that was responsible for all this morbidity. Advanced Western societies acquired better nutrition in great part through the control of environmental sanitation and personal hygiene. Our problem in the Third World is to go back a little on our early footsteps and try to improve the environment, because 20 years after we started nutrition programmes and all kinds of experimental field studies, no convincing evidence has come up revealing the expected effect of nutrition programmes. Whenever a decrease in mortality was observed, vaccination and water supply were measures also under way. Field studies so far do not give clear-cut answers in this regard.

Tyrrell: Some of the beautiful studies done at the NIH, following the brief diarrhoea induced by the type I OF viruses, have demonstrated prolonged difficulties of absorption in volunteers who otherwise seem well, which may indicate their potential for precipitating malnutrition (Blacklow 1972).

Harries: On a more specific point, how often do you think Giardia is a primary agent in the disease process in your part of the world, Dr Mata?

Mata: I don't think we know enough about the significance of Giardia or Dientamoeba fragilis or even Entamoeba histolytica in the endemic diarrhoeas; data from our prospective study have not been analysed yet. We tend to think that first experiences with the agent may be important; later colonization may not be as important for morbidity. This is an impression from the examination of displayed data; the final analysis hasn't been made.

Marshall: I was rather surprised at what appeared to be a low incidence of exanthematous disease in the children, Dr Mata. What immunization programmes were part of this programme?

Mata: I wouldn't say that there was a low incidence of this. You would be unimpressed if you visited the health centre because most complaints are diarrhoea, dysentery and respiratory infections. But when you examine the records of the cohorts of children and how they get exposed to and manifest exanthematous disease, you find that almost all get natural measles in the first three or four years of life. You detect rubella in about a quarter of them but much would be subclinical. There are many episodes of febrile vesicular lesions associated with enteroviruses. Guatemala was certainly a very special country in which to do this research, in the sense that when the study began in 1964 measles vaccine was not yet available, and it was available in 1968 or 1969. 
After we held a symposium on measles, the government began a mass immunization campaign. There were no systematic immunization programmes in the country during the collection of the data produced by our long-term study.

Hendriekse: Did the contact over a long period of time with a relatively large medical caucus in the village have any measurable effect on population behaviour over the 10-year period, in terms of the health measures, general standards of living, and use of medical facilities? Was this measurable or noticeable in any way?

Mata: There were many sociological and anthropological aspects that we could not measure, but changes did occur in the community. Some people, particularly social scientists, said we were disrupting certain features of village life. I know this is possible. Medically, I don't know whether the people have changed; it would be difficult to know. The heights and weights attained by children at seven years of age, the frequency of low birth weight babies, or the mean birth weight, the overall rates of infectious diseases, the dietary pattern, did not change over 10 years. The data show that whatever we did to improve the community probably was neutralized by other evolving conditions. We say that there were no significant changes in the community, which was a very sad thing. This was not an intervention study (Mata et al. 1975).

Millen: In your lists of infections you don't mention any urinary tract infections. Are they really absent?

Mata: We detected urinary tract infections on clinical grounds; children with fever were clinically and bacteriologically diagnosed. In general, the incidence was very low. In women it is very high (Urrutia et al. 1975).

Bullen: Has this anything to do with breast-feeding? Breast-fed children apparently get fewer urinary tract infections (p. 165).

Mata: We don't know, because we have no control group. The few cases we saw were in the first and second year of life; we didn't see any in the third year of life. Yet $25 \%$ of the women have bacteriuria during pregnancy (Urrutia et al. 1975).

Taylor: Your study is a fascinating one, Dr Mata. How many people did you use to carry out this study, how much were you involved personally in it, and how long did it take you?

Mata: It was a mushrooming operation! It began with a grant of US $\$ 30000$ a year with a physician, myself, one nurse (then we hired a second and a third one) and two or three laboratory technicians. We recruited about 50 newborns a year. We were recruiting about 80 in 1974 . The study still continues. At the peak of the study about 22 people were directly engaged. We built a laboratory in the village. in the first two years, I spent almost every day either in the village or in the headquarters at the virus and cell culture laboratory. We 
trained every technician personally; all the techniques were established by ourselves. When the study was running smoothly I visited the village about twice a week. Later we had two physicians; one visited the village every day.

Bull: We have had a series of papers earlier in this symposium in which one or another aetiological agent has been considered. In no case have I found a situation where all the possible agents have been looked at in the same population. This presents an appalling problem, because to look for viral agents, for all the $E$. coli possibilities and for all the other parasites will be a terrible job. Has anyone any plans for a solution to this?

Hamilton: I could comment on that in conjunction with our studies on hospitalized infants with viral enteritis. These children to the best of our ability were screened for all aetiological agents likely to occur in our region; we looked for enterotoxin-producing organisms in addition to pathogenic bacteria. Viral enteritis did not affect the bacterial flora, either invasive or enterotoxin-producing species. To do such a study on a widespread community basis would be difficult with existing diagnostic techniques.

Tyrrell: This sort of problem was encountered by virologists faced with isolating large numbers of enteroviruses in the past. It is not only the technical problem of getting all the tests done on numbers of patients with diarrhoea, but also the problem of selecting the comparison group and of trying to decide which of all the organisms present are relevant, and all this requires careful epidemiological design. Such a problem was met by the NIH group in Junior Village where numerous respiratory pathogens occurred simultaneously. They had to make two types of analysis, a 'vertical' one in which they compared sick and well children at any one time and saw how many carried each virus and looked for significant differences in frequency; and also a 'longitudinal' analysis in which they related the appearance and disappearance of agents to whether the children had or had not symptoms. There is a great deal of information already to say that you are likely to find several different intestinal pathogens circulating simultaneously, except in the relatively most hygienic areas of the world; we must therefore look for situations in which we can do two things. Firstly, to decide whether a given agent is a pathogen at all ; is there enough evidence to say that it can cause disease? For this we may need rather 'clean' environments where you can find a good comparison group. Secondly, we can tackle areas where there are a lot of pathogens circulating together; though it may be impossible to determine which one is making a child sick at a particular time, yet we may be able to work out what the relative importance of each is.

Taylor: It is important to stress that the work we do is entirely dependent on the samples we examine. Therefore one's sampling technique is of major 
importance. Surveys where people say that they have looked at 10 swabs from 10 people in 10 different hospitals are absolutely useless, unless the person taking samples has been trained by the person who is wanting the answers-in other words, has direct responsibility. To a certain extent one can get over this, because if one is doing a survey of thousands of specimens one may be able to iron out second-rate sampling. If one is only looking at 50 specimens it has to be first-class sampling under the personal direction, as Dr Mata pointed out, of the person interested in the investigation. This is where so many people go wrong, both in ordinary hospital practice and in research.

Mata: Our field study on health and growth began as a study of the aetiology of diarrhoeal disease; at the beginning we were frustrated at seeing the result we were obtaining - that is, the finding of many agents in the cases and controls as well. We went to the village because diarrhoea] agents were there. I think that if the complex aetiology of the diarrhoea is to be solved it will be done in a very advanced societal group where one can afford to study the entrance of isolated agents with as little interference as possible by the background population of bacteria, parasites and viruses, which is so characteristic of underdeveloped societies. It has to be a prospective study, beginning at birth, and carried out-preferably in an Institute of Diarrhoea! by a variety of individuals; immunologists, bacteriologists, virologists and so on.

\section{References}

AGUiRRe, A. \& PRADilla, A. (1973) Newer community approaches in Colombia, in Nutrition Programmes for Preschool Children (Reports of a Conference held in Zagreb, Yugoslavia, 1971) (Jelliffe, D. B. \& Jelliffe, E. F. P., eds.), pp. 270-279

BLACKLOW, N. R. (1972) Acute infectious nonbacterial gastroenteritis: etiology and pathogenesis. Ann. Intern. Med. 76, 993-1008

Ciba Foundation (1967) Nutrition and Infection (Ciba Found. Study Group 31), Churchill, London

DOSSETOR, J. F. B. \& WHITTLE, H. C. (1975) Protein-losing enteropathy and malabsorption in acute measles enteritis. Br, Med. J., 2, 592

FlOYD, T. M., Higgins, A. R. \& KADER, M. A. (1956) Studies in shigellosis. V. The relationship of age to the incidence of Shigella infections in Egyptian children, with special reference to shigellosis in the newborn and in infants in the first six months of life. Am. J. Trop. Med. Hyg. 5, i 19-130

HOLLISTER, A. C., Becx, M. D., GrtrasonN, A. M. \& HEMPHILL, E. C. (1955) Influence of water availability on Shigella prevalence in children of farm labor families. Am. J. Public Health 45, 354-362

MATA, L. J., FERNANDEZ, R. \& URRUTIA, J. J. (1969) Infeccion del intestino por bacteria enteropatagenas en ninos de una aldea de Guatemala, durante los tres primeros años de vida. Rev. Latinoam. Microbial. Parasitol. //, 102-109

MATA, L. J., URRUTIA, .1. J., KRONMAL, R. A. \& JOPLIN, C. (1975) Survival and physical growth in infancy and early childhood. Am. J. Dis. Child. 129,561-566 
PLATT, B. G. (1964) Malnutrition in African mothers, infants and young children, in Report of the Second Inter-African (CCTA) Conference on Nutrition, Gambia, 1952, p. 24, H.M. Stationery Office, London

SCHEIfELE, D. W. \& FORBES, C. E. (1972) Prolonged giant cell excretion in severe African measles. Pediatrics 50, 867-873

URRUTIA, J. J., M ATA, L. J., TRENT, F., CRUZ, J. R., VILLATORD, E. \& ALEXANDER, R. E. ( 1975) Infection and low birth weight in a developing country. Am. J. Dis. Child. 129, 558-561 